\title{
Model Lean Six Sigma di Industri Farmasi
}

Authors:

Rini Mulyani Sari

Evan Nugraha $^{2}$

Affiliations:

${ }^{1}$ Teknik Industri, Fakultas

Teknik, Universitas

Widyatama, Bandung,

Indonesia

${ }^{2}$ Teknik Industri, Fakultas

Teknik, Universitas

Muhammadiyah Bandung,

Indonesia

Corresponding Author:

Rini Mulyani Sari

Emails:

1rini.mulyani@widyatama.ac.id

2noe.rievan@gmail.com

Article History:

Received: February 12, 2018

Revised : April 25, 2018

Accepted: June 3, 2018

How to cite this article: Sari, R. M., \& Nugraha, E. (2018). Model Lean Six Sigma di Industri Farmasi. Organum: Jurnal Saintifik Manajemen dan Akuntansi, 1(1), 1-7. doi: https://doi.org/10.35138/organu m.v1i1.25

Journal Homepage: ejournal.winayamukti.ac.id/ind ex.php/Organum

\section{Copyright:}

C 2018 . Published by Organum: Jurnal Saintifik Manajemen dan Akuntansi. Faculty of Economics and Business. Winaya Mukti University.

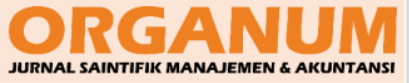

Abstract. Indonesia is one of the countries in the ASEAN Economic Community (AEC). To boost competitiveness and benefit from changes in the global industrial system at revolutionary era, lean six sigma approach to production systems in the pharmaceutical industry was used. The goal is to analyze the existing conditions, user expectations, how to overcome the obstacles that occur and the formulation of strengthening strategies on the production system of soft capsule lines. The method used is an explanatory case study of production systems in the pharmaceutical industry using lean six sigma approach. The results of the research are the existing conditions of the production system have not met expectations, user expectations systems are not well understood, formulation ways to overcome the constraints that occur in the production system and the formulation of the strengthening pharmaceutical industry's production system strategy using lean six sigma approach.

Keywords: Lean; pharmacaeutical industry; asean economic community; soft capsule; six sigma.

Abstrak. Indonesia termasuk salah negara dalam Masyarakat Ekonomi ASEAN (MEA). Dalam upaya mendongkrak daya saing dan memperoleh manfaat dari perubahan sistem industri global di era revolusi saat ini maka digunakan pendekatan lean six sigma pada sistem produksi di industri farmasi. Tujuan yang ingin dicapai adalah menganalisis kondisi existing, ekspektasi user, cara mengatasi kendala yang terjadi dan rumusan penguatan strategi pada`sistem produksi lini kapsul lunak. Metode yang digunakan adalah studi kasus eksplanatori sistem produksi di industri farmasi dengan menggunakan pendekatan lean six sigma. Hasil penelitian adalah kondisi existing sistem produksi belum memenuhi ekspektasi, sistem ekspektasi user belum dipahami dengan baik, rumusan cara mengatasi kendala yang terjadi pada sistem produksi, dan rumusan penguatan strategi sistem produksi industri farmasi dengan menggunakan pendekatan lean six sigma.

Kata Kunci: Lean; industri farmasi; masyarakat ekonomi asean; kapsul lunak; six sigma.

\section{Pendahuluan}

$\Lambda$ charya, et. al, (2014) melakukan penelitian dengan lokus industri farmasi skala besar, alat analisis statistik, dengan menggunakan pendekatan six sigma dapat menganalisis kapabilitas proses dan berimplikasi pada reduksi kekerasan pelapisan logam. Kare, et. al, (2014) melakukan penelitian dengan lokus industri farmasi skala besar, alat analisis statistik, dengan menggunakan pendekatan six sigma dapat mereduksi waktu siklus dan biaya secara signifikan. Hussain, Jamshaid dan Sohail, (2014) melakukan penelitian dengan lokus industri tekstil, alat analisis statistik, dengan menggunakan pendekatan six sigma akan meningkatkan kualitas produk. Jilcha dan Kitaw, 
(2015) melakukan penelitian dengan lokus industri kimia, alat analisis studi kasus eksploratori, dengan menggunakan pendekatan lean production dapat meningkatkan daya saing industri kimia. Sujova, Simanova dan Marcinekova, (2016) melakukan penelitian dengan lokus penelitian industri furniture, alat analisis statistik, dengan menggunakan pendekatan six sigma akan meningkatkan performansi bisnis dan profit perusahaan.

Dari penelitian sebelumnya terlihat bahwa terdapat empat penelitian menggunakan pendekatan six sigma dan satu penelitian menggunakan pendekatan lean production serta belum ada penelitian yang menggunakan pendekatan lean six sigma seperti yang digunakan dalam penelitian ini. Walaupun terdapat lokus penelitian yang sama yaitu industri farmasi namun yang dijadikan lokus dalam penelitian ini adalah industri farmasi obat generik skala menengah yang menjadi anggota tender. Walaupun menggunakan alat analisis yang sama yaitu studi kasus eksploratori namun yang menjadi fokus penelitian berbeda yaitu sistem produksi lini kapsul lunak.

Gap yang terjadi dalam penelitian dilihat dalam tiga kategori yaitu ketidaksesuaian tingkat ketepatan waktu, ketidaksesuaian tingkat kesiapan mesin di lantai produksi dan ketidaksesuaian tingkat kualitas produksi. Untuk tingkat ketepatan waktu menggunakan empat indikator antara lain waktu baku, waktu siklus, waktu pengujian dan lead time. Untuk tingkat kesiapan mesin di lantai produksi menggunakan indikator nilai Overall Equipment Effectiveness (OEE). Sedangkan untuk tingkat kualitas produksi menggunakan indikator level sigma dan nilai yield.

Produk yang dijadikan studi kasus adalah Vitamin A 200.000 IU dengan bentuk sediaan kapsul lunak. Produk tersebut dijadikan studi kasus karena merupakan salah satu produk dengan jumlah permintaan terbesar pada tahun 2015-2016 yaitu 62 jutaan kapsul. Selain itu produk Vitamin A 200.000 IU merupakan jenis obat generik dan merupakan produk reguler. Pada tahap observasi awal ditemukan beberapa masalah diantaranya peningkatan waktu baku sebesar 18,45\%; peningkatan waktu siklus sebesar 10,93\%; peningkatan lead time sebesar 19,95\%; peningkatan waktu uji sebesar 11,41\%; penurunan nilai OEE sebesar 7,37\%; penurunan yield sebesar $0,05 \%$; dan penurunan level sigma sebesar $5,44 \%$ (Hasil olahan penelitian, 2017). Berdasarkan gambaran di atas maka dilakukan penelitian yang bersifat ekploratori, sehingga didapatkan pemahaman yang lebih mendalam mengenai model lean six sigma di industri farmasi khususnya pada sistem produksi lini kapsul lunak sehingga dapat menghasilkan nilai tambah bagi konsumen (Triyatmoko, 2009). Diharapkan dengan model lean six sigma yang dibuat dapat meningkatkan ketepatan waktu, kuantitas dan kualitas yang tinggi (Zaroni, 2016).

Pertanyaan yang akan dijawab dalam penelitian ini adalah bagaimana implementasi lean six sigma yang berjalan?; bagaimana implementasi lean six sigma di yang diingkan oleh pengguna?; bagaimana cara mengatasi kendala dalam implementasi lean six sigma?; dan bagaimana rumusan penguatan strategi implementasi lean six sigma di industri farmasi khususnya lini kapsul lunak?

Tujuan yang hendak dicapai dalam penelitian ini adalah untuk mengetahui, mengkaji dan menganalisis implementasi lean six sigma yang berjalan; implementasi lean six sigma yang diinginkan oleh user; cara mengatasi kendala implementasi lean six sigma; dan rumusan penguatan strategi implementasi lean six sigma di industri farmasi khususnya lini kapsul lunak.

\section{Kajian Literatur}

Lean six sigma merupakan perpaduan antara lean management dan six sigma. Dimana lean management akan meningkatkan produktivitas sedangkan 
pendekatan six sigma akan meningkatkan kualitas produk yang dihasilkan. Menurut Bruce Nelson (2016: 36) lean management didefinisikan sebagai sekumpulan technical analysis tools untuk memperpendek proses lead time dengan meningkatkan produktivitas mesin, manpower dan material. Lean management merupakan sistem manajemen yang mendayagunakan setiap karyawan untuk mencapai tujuan organisasi dengan konsep terencana (Chairini, 2016: 46).

Menurut Gasperz (2011: 52) six sigma adalah upaya mengejar keunggulan dalam kepuasan pelanggan melalui peningkatan kualitas terus menerus; sasaran kualitas dramatik yang memiliki kapabilitas produk dan proses 3,4 DPMO atau 99,99966\% bebas cacat; ukuran yang mengindikasikan bagaimana suatu proses produksi industri; dan strategi terobosan yang memungkinkan perusahaan melakukan peningkatan luar biasa di tingkat bawah melalui proyek-proyek six sigma.

Didalam penerapan six sigma ada beberapa inti dan filosofi penting yang perlu diperhatikan yaitu (Evan dan Lindsay, 2008: 4-5) selalu berpikir dalam kerangka proses bisnis utama serta kebutuhan pelanggan dengan tetap berfokus pada tujuan strategis perusahaan; memusatkan perhatian pada para pendukung perusahaan yang bertanggung jawab menyukseskan proyek-proyek penting, mendukung kerja kelompok, membantu mengatasi keengganan untuk berubah dan menggalang sumber daya; menekankan sistem pengukuran yang bisa dikuantifikasi, seperti cacat per satu juta kemungkinan (Defect Per Million Opportunities) yang bisa diterapkan di setiap bagian perusahaan seperti produksi, rekayasa, administrasi, piranti lunak dan lain-lain; dan memastikan bahwa sistem pengukuran yang tepat dapat teridentifikasi di awal setiap proses serta memastikan bahwa sistem tersebut berfokus pada pencapaian bisnis, sehingga dapat memberikan sistem insentif dan akuntabilitas.

Sehingga penelitian ini akan melihat sistem produksi di industri farmasi khususnya lini kapsul lunak dengan menggunakan pendekatan lean six sigma. Penelitian ini merupakan penelitian multi stage dimana akan digambarkan terlebih dahulu kondisi eksisting yang terjadi pada fase define, kemudian didefinisikan gap yang terjadi pada fase measure, dianalisis penyebab terjadinya gap pada fase analyze, dirancang tindakan perbaikan pada fase improve, kemudian diukur kembali hasil dari tindakan perbaikan, apabila sudah memenuhi ekspektasi maka langsung masuk fase control dan dibakukan dalam Standard Operating Procedure (SOP) namun apabila belum memenuhi ekspektasi maka akan dianalisis kembali dalam fase analyze.

Proposisi yang akan diuji dalam penelitian ini adalah implementasi lean six sigma yang berjalan di belum memenuhi ekspektasi; implementasi lean six sigma yang diharapkan user belum dipahami dengan baik; perlu dirumuskan cara mengatasi kendala-kendala dalam implementasi lean six sigma; dan perlu dirumuskan penguatan strategi inplementasi lean six sigma di industri farmasi khususnya pada lini kapsul lunak.

\section{Metode Penelitian}

Metode yang dipergunakan dalam penelitian ini adalah metode penelitian kualitatif, dengan mengambil studi kasus tunggal implementasi lean six sigma di industri farmasi (studi kasus mengenai kapsul lunak). Sumber data yang digunakan adalah data primer (observasi, wawancara dan focus group discussion) serta data sekunder (studi dokumentasi).

Teknik pengumpulan data yang digunakan dalam penelitian ini antara lain,

1. Observasi menghasilkan data: aktivitas produksi pada stasiun kerja penimbangan, stasiun kerja massa tambahan cangkang, stasiun kerja 
pelelehan cangkang gelatin, stasiun kerja pencampuran obat, stasiun kerja encapsulating, stasiun kerja pengeringan, stasiun kerja pengemasan primer, tasiun kerja coding etiket dan stasiun kerja pengemasan sekunder; waste yang terjadi pada ke-9 stasiun kerja; jumlah operator produksi pada ke-9 stasiun kerja; dan jumlah dan jenis produk rework pada lini kapsul lunak.

2. Studi dokumentasi menghasilkan data: waktu proses pada stasiun kerja penimbangan, stasiun kerja massa tambahan cangkang, stasiun kerja pelelehan cangkang gelatin, stasiun kerja pencampuran obat, stasiun kerja encapsulating, stasiun kerja pengeringan, stasiun kerja pengemasan primer, tasiun kerja coding etiket dan stasiun kerja pengemasan sekunder; waktu proses pengujian mikrobiologi; yield pada ke-9 stasiun kerja; dan waktu release obat jadi sediaan kapsul lunak ke Gudang Obat Jadi (GOJ).

3. Focus Group Discussion terhadap divisi: Supply Chain Management perihal prosedur pembuatan jadwal produksi lini kapsul lunak; Produksi perihal perolehan cycle time, overall equipment effectiveness dan yield lini kapsul lunak; Quality control perihal prosedur quality control per stasiun kerja, prosedur pengujian mikrobiologi serta penyebab defect pada produk sediaan kapsul lunak; dan Quality assurance perihal temuan pada batch record mengenai ketidaksesuaian waktu proses, waktu pengujian serta waktu release produk jadi ke Gudang Obat Jadi (GOJ).

4. Wawancara mengenai pelaksanaan pilar total productive maintenance, total flow management, total human management, total service management dan total quality management. Untuk wawancara dilakukan dengan menggunakan metode snowball sampling mulai dari level supervisor, manajer hingga senior manajer. Hal ini dilakukan agar hasil wawancara benar- benar merefleksikan kondisi yang terjadi pada tempat penelitian sehingga hasil penelitian diharapkan benar-benar akurat dan dapat dipertanggungjawabkan.

Berikut adalah garis besar teknik analisis data yang dilakukan antara lain: menganalisis setiap data yang relevan; menganalisis bagaimana proses pembentukan model lean six sigma di industri farmasi khususnya lini kapsul lunak; melakukan chain of evidence; melakukan triangulasi pada saat pengumpulan data; dan melakukan pengujian kredibilitas data.

Terdapat tiga variabel yang diukur yaitu untuk peningkatan produktivitas dilakukan dengan mengukur tingkat ketepatan waktu dengan indikator waktu baku proses, waktu siklus, lead time dan waktu pengujian mikrobiologi dan tingkat kesiapan mesin di lantai produksi dengan indikator nilai OEE. Sedangkan untuk peningkatan kualitas menggunakan indikator nilai yield dan level sigma.

\section{Hasil dan Pembahasan}

Hasil dari penelitian ini berupa pembuktian proposisi yang telah dirumuskan sebelumnya.

\section{Proposisi 1: implementasi lean six sigma yang berjalan di lini kapsul lunak belum memenuhi ekspektasi.}

Untuk tingkat ketepatan waktu mengalami peningkatan waktu baku proses, waktu siklus, lead time dan waktu pengujian yang berkisar antara 10,93\% hingga $19,95 \%$. Waktu baku proses didapatkan dari waktu baku per stasiun kerja pada batch record produk vitamin A 200.000 IU. Kemudian dicari rata-rata dari ke-52 batch record vitamin A 200.000 IU pada tahun 2015 dan tahun 2016. Setelah itu dilihat berapa prosentase peningkatan rata-rata waktu baku proses kedua tahun tersebut.

Untuk waktu siklus didapatkan dari penjumlahan antara waktu baku ke-9 stasiun kerja pembuatan produk Vitamin A 
200.000 IU. Untuk waktu pengujian mikrobiologi didapatkan dari lamanya waktu yang diperlukan mulai dari pengujian dimulai sampai release hasil pengujian. Sedangkan untuk lead time didapatkan dari hasil penjumlahan antara waktu siklus dengan waktu tunggu antara stasiun kerja.

Untuk tingkat kesiapan mesin di lantai produksi mengalami penurunan nilai overall equipment effectiveness sebesar $7,37 \%$. Nilai OEE didapatkan dari rata-rata perhitungan nilai OEE per stasiun kerja pada tahun 2015 dan tahun 2016. Kemudian dilihat berapa persentase penurunan nilai OEE yang terjadi.

Untuk tingkat kualitas produksi mengalami penurunan nilai yield dan level sigma berkisar antara $0,05 \%$ hingga $5,44 \%$. Untuk nilai yield didapatkan dari rata-rata nilai yield stasiun filling dan packing produk vitamin A 200.000 IU. Kemudian dilihat berapa prosentase penurunan nilai yield yang terjadi pada tahun 2015 dan tahun 2016. Sedangkan untuk level sigma didapatkan dari rata-rata level sigma untuk tingkat ketepatan waktu, tingkat kesiapan mesin di lantai produksi dan nilai yield.

Berdasarkan penyesuaian pola diatas antara perumusan proposisi pertama dengan hasil temuan penelitian dapat disimpulkan bahwa Proposisi pertama terbukti sepenuhnya yaitu implementasi lean six sigma yang berjalan di lini kapsul lunak belum memenuhi ekspektasi.

Proposisi 2: implementasi lean six sigma di lini kapsul lunak yang diinginkan user belum dipahami dengan baik.

Untuk tingkat ketepatan waktu terjadi gap pada waktu baku proses, waktu siklus, lead time dan waktu pengujian yang berkisar antara 5,79\% hingga 37,72\%. Prosentase tingkat ketepatan waktu didapatkan dari perbandingan antara perolehan rata-rata tingkat ketepatan waktu pada tahun 2015 dan tahun 2016 dengan standar yang berlaku.

Untuk tingkat kesiapan mesin di lantai produksi mengalami gap pada nilai overall equipment effectiveness sebesar $39,29 \%$. Nilai ini diperoleh dari perbandingan antara nilai rata-rata $\mathrm{OEE}$ tahun 2015 dan tahun 2016 dengan standar yang berlaku yaitu sebesar $85 \%$.

Untuk tingkat kualitas produksi mengalami gap pada nilai yield dan level sigma berkisar antara $0,76 \%$ hingga $61,85 \%$. Untuk nilai yield didapatkan dari perbandingan antara rata-rata nilai yield tahun 2015 dan tahun 2016 dengan standar yang berlaku yaitu 99,9\%, sedangkan untuk level sigma didapatkan dari perbandingan antara rata-rata perolehan level sigma tahun 2015 dan tahun 2016 dengan standar yang berlaku yaitu level enam sigma.

Berdasarkan penyesuaian pola diatas antara perumusan proposisi kedua dengan hasil temuan penelitian dapat disimpulkan bahwa proposisi kedua terbukti sepenuhnya yaitu implementasi lean six sigma di lini kapsul lunak belum dipahami dengan baik.

Proposisi 3: perlu dirumuskan cara mengatasi kendala-kendala dalam implementasi lean six sigma di lini kapsul lunak.

Untuk ketidaksesuaian waktu baku proses dan waktu siklus penyebab potensial adalah waktu baku proses melebihi standard work hours yang berlaku. Tindakan perbaikan yang dilakukan adalah supervisor produksi melakukan sosialisasi prosedur tetap (protap) yang berlaku di tiap stasiun kerja mengalami penurunan Risk Priority Number (RPN) sebesar 61,73\%.

Untuk ketidaksesuaian lead time penyebab potensial adalah ketidaksesuaian pelaksanaan jadwal produksi. Tindakan perbaikan yang dilakukan adalah dilakukan pengecekan ulang jadwal produksi tiga hati sebelum pelaksanaan oleh supervisor produksi mengalami penurunan RPN sebesar 68,25\%.

Untuk ketidaksesuaian waktu pengujian penyebab potensial adalah ketidaksesuaian pelaksanaan jadwal 
pengujian mikrobiologi. Tindakan perbaikan yang dilakukan adalah menambah jumlah peralatan uji mikrobiologi di laboratorium quality control mengalami penurunan RPN sebesar $51,79 \%$.

Untuk ketidaksesuaian nilai Overall Equipment Effectiveness penyebab potensial adalah sering terjadi penghentian sementara mesin di lantai produksi. Tindakan perbaikan yang dilakukan adalah meningkatkan kesadaran operator produksi mengenai pentingnya autonomous maintenance mengalami penurunan RPN sebesar 52,38\%.

Untuk ketidaksesuaian nilai yield dan level sigma penyebab potensial adalah ketidaksesuaian pemeriksaan output yang dihasilkan dalam satu batch produksi. Tindakan perbaikan yang dilakukan adalah meningkatkan kesadaran operator akan pentingnya ketelitian dalam menjalankan tugasnya mengalami penurunan RPN sebesar $47,92 \%$.

Berdasarkan penyesuaian pola diatas antara perumusan proposisi ketiga dengan hasil temuan penelitian dapat disimpulkan bahwa proposisi ketiga terbukti sepenuhnya yaitu perlu dirumuskan cara mengatasi kendala-kendala dalam implementasi lean six sigma di lini kapsul lunak.

\section{Proposisi 4: perlu dirumuskan strategi} implementasi lean six sigma di industri farmasi khususnya lini kapsul lunak.

Untuk tingkat ketepatan waktu memiliki rincian sebagai berikut: kondisi sebelum perbaikan mengalami peningkatan waktu baku proses sebesar $18,45 \%$, sedangkan setelah perbaikan mengalami penurunan waktu baku proses sebesar 6\%; kondisi sebelum perbaikan mengalami peningkatan waktu siklus sebesar 10,93\%, sedangkan setelah perbaikan mengalami penurunan waktu siklus sebesar 5,6\%; kondisi sebelum perbaikan mengalami peningkatan lead time sebesar 19,95\%, sedangkan setelah perbaikan mengalami penurunan lead time sebesar 41,54\%; dan kondisi sebelum perbaikan mengalami peningkatan waktu pengujian mikrobiologi sebesar 11,41\%, sedangkan setelah perbaikan mengalami penurunan waktu pengujian mikrobiologi sebesar $23,31 \%$.

Untuk tingkat kesiapan mesin di lantai produksi sebelum perbaikan mengalami penurunan nilai OEE sebesar $7,37 \%$, sedangkan setelah perbaikan mengalami peningkatan nilai OEE sebesar $36,04 \%$.

Untuk tingkat kualitas produksi memiliki rincian sebagai berikut: kondisi sebelum perbaikan mengalami penurunan nilai yield sebesar $0,05 \%$, sedangkan setelah perbaikan mengalami peningkatan nilai yield sebesar $0,62 \%$ dan kondisi sebelum perbaikan mengalami penurunan level sigma sebesar 5,44\%, sedangkan setelah perbaikan mengalami peningkatan level sigma sebesar $19,49 \%$.

Berdasarkan penyesuaian pola diatas antara perumusan proposisi keempat dengan hasil temuan penelitian dapat disimpulkan bahwa proposisi keempat terbukti sepenuhnya yaitu perlu dirumuskan strategi implementasi lean six sigma di industri farmasi khususnya lini kapsul lunak.

\section{Kesimpulan}

Simpulan dari penelitian ini adalah sebagai berikut.

1. Implementasi lean six sigma yang berjalan di lini kapsul lunak belum sesuai dengan ekspektasi terbukti dengan adanya peningkatan waktu baku proses, waktu siklus, lead time dan waktu pengujian mikrobiologi, penurunan nilai OEE, nilai yield dan level sigma.

2. Implementasi lean six sigma di lini kapsul lunak yang diinginkan user belum dipahami dengan baik terbukti dengan adanya gap pada waktu baku proses, waktu siklus, lead time, waktu pengujian mikrobiologi, nilai $\mathrm{OEE}$, nilai yield dan level sigma.

3. Perlu dirumuskan cara mengatasi kendala-kendala dalam implementasi 
lean six sigma di lini kapsul lunak terbukti setelah dilakukan perbaikan terjadi penurunan RPN ketidaksesuaian waktu baku proses dan waktu siklus, ketidaksesuaian lead time, ketidaksesuaian waktu pengujian, ketidaksesuaian nilai OEE, ketidaksesuaian nilai yield dan level sigma.

4. Perlu dirumuskan strategi implementasi lean six sigma di industri farmasi khususnya lini kapsul lunak terbukti dengan adanya penurunan waktu baku proses, waktu siklus, lead time dan waktu pengujian mikrobiologi untuk kondisi setelah perbaikan; dan peningkatan nilai OEE, nilai yield dan level sigma untuk kondisi setelah perbaikan

\section{Daftar Pustaka}

Acharya, S. K., Laha, A., Acharya P. K., \& Tripathy, S. (2015). Applications of Six Sigma in Pharmaceutical Industries. International Journal of Research in Mechanical Engineering and Technology, 5(1), 22-28. Diakses dari http://www.ijrmet.com/vol5issue1/s pl1/4-Sujit-Kumar-Acharya.pdf

Chiarini, A., Found, P., \& Rich, N. (2016). Understanding The Lean Enterprises: Strategies, Methodologies, and Principles for a More Responsive Organization. Cham: Springer.

Evans, J. R., \& Lindsay, W. M. (2008). The Management and Control of Quality (7th Ed.). Ohio: Thomson South-Western.

Gasperz, V. (2011). Lean Six Sigma for Manufacturing and Service Industries. Bogor: Penerbit Vinchristo Publication.

Hussain, T., Jamshaid, H., \& Sohail, A. (2014). Reducing Defects in Textile Weaving by Applying Six Sigma
Methodology: A Case Study. International Journal Six Sigma and Competitive Advantage, 8(2), 95$103 . \quad$ doi: https://doi.org/10.1504/IJSSCA.201 4.064254

Jilcha, K., \& Kitaw, D. (2015). Lean Philosophy for Global Competitiveness in Ethiopia Chemical Industries: Review. Journal of Computer Science System Biology, 8(6), 304 - 321. doi: https://doi.org/10.4172/jcsb.100020 $\underline{5}$

Kare, P. T., Bhor, N. J., Bhusare S. E., \& Chaudhari R. A. (2014). Six Sigma: an Emerging Approach in Pharma Industry. International Journal of Pure \& Applied Bioscience, 2(5), 132-138. Diakses dari http://www.ijpab.com/form/2014\%2 0Volume $\% 202, \% 20$ issue $\% 205 /$ IJPA B-2014-2-5-132-138.pdf

Nelson, B., \& Sproull, B. (2016). Focus \& Leverage The Critical Methodology for Theory of Constraint, Lean \& Six Sigma (TLS). Boca Raton: FL CRC Press.

Sujova, A., Simanova, L., \& Marcinekova, K. (2016). Sustainable Process performance by Application of Six Sigma Concepts: The Research Study of Two Industrial Case. Sustainability Journal, 8(260), 1-21. doi: https://doi.org/10.3390/su8030260

Yatmoko, T. (29 Mei 2009). Lean Thinking. Diakses dari https://triyatmoko.wordpress.com/2 009/05/29/lean-thinking/

Zaroni, Z. (4 Januari 2016). Pendekatan Cost Management dalam Mengelola Inventory (Bagian \#2). Diakses dari https://supplychainindonesia.com/n ew/pendekatan-cost-managementdalam-mengelola-inventory-bagian$\underline{2 l}$ 